\title{
Fluoridation of water supplies and cancer mortality III: A re-examination of mortality in cities in the USA
}

\author{
LEO KINLEN* \\ From the CRC Cancer Epidemiology Research Group, University of Oxford
}

\author{
RICHARD DOLL \\ From the ICRF Cancer Epidemiology and Clinical Trials Unit, University of Oxford
}

Differences in trends in crude mortality rates from cancer between 10 fluoridated and 10 non-fluoridated cities in the USA were claimed by Yiamouyiannis and Burk to indicate that cancer mortality had risen to an unusual extent in the fluoridated cities. ${ }^{2}$ These claims, which were widely publicised, prompted us, among others, to examine all relevant published data for the cities in question. When, however, account was taken of the demographic differences between the two groups of cities and the way they changed, there was no suggestion of a greater rise in cancer mortality rates (standardised by the indirect method) in the fluoridated than in the non-fluoridated cities. ${ }^{34}$ Later Yiamouyiannis and Burk reported that their earlier claim was supported by unpublished data obtained from the vital statistics offices and health departments of the cities concerned when the direct method was used to standardise the mortality rates. ${ }^{5}$ In this analysis, however, men and women and whites and non-whites were classed together in broad age groups $(0-24,25-44$, etc.) and this analysis did not take account of the changes in the sex and ethnic structure of the populations under comparison or adequate account of changes in their age structure. Although these shortcomings were repeatedly pointed out, ${ }^{\text {br }}$ the claims of Yiamouyiannis and Burk have continued to be published in many parts of the world and extreme statements made about the merits of the direct over the indirect method of standardisation-even when the former is used, as in this case, in a crude and inappropriate manner. Indeed, official inquiries have been instigated in several places including Victoria (Australia) and Minnesota and Kansas (USA).

Through the National Center for Health Statistics, we have now obtained the numbers of deaths from cancer in the cities concerned by sex, ethnic group, and 10-year age group for 1970 so that the direct method of standardisation can be applied properly

*Gibb Fellow of the Cancer Research Campaign. and the results compared with those obtained by the indirect method. We have also analysed the data for all three census years, 1950,1960 , and 1970 , in a variety of alternative ways and in addition have used what, in our opinion, is a more appropriate set of control cities in the analysis.

\section{Results}

In Table 1(a) are shown the ratios of observed to expected numbers obtained when the US national mortality rates for each of the census years 1950 , 1960 , and 1970 are used as the standard rates and applied successively to the populations of the 10 fluoridated and the 10 non-fluoridated cities (set 1) chosen by Yiamouyiannis and Burk. Whichever rates are used the results are the same, with no indication of a greater deterioration of the situation in the fluoridated cities than in the non-fluoridated cities. When mortality rates are used for the same years as those of the observed numbers, from 1950 to 1970 , the observed to expected ratios fell more in the fluoridated than in the non-fluoridated cities. When the same mortality rates are used throughout, the ratios increased with time over the period 1950 to 1970 in each case, but by a smaller percentage in the fluoridated cities than in the non-fluoridated cities irrespective of whether the 1950,1960 , or 1970 US rates were used as the standard.

EXCLUSION OF ATLANTA AND SEATTLE Inclusion of Atlanta and Seattle in the group of non-fluoridated cities has been criticised by Yiamouyiannis because their water supplies began to be fluoridated in the period December 1969 to October 1970 (notwithstanding the fact that two of their control cities, San Diego and Kansas (Missouri), were also fluoridated for a short period, in 1952-4 and 1962-4 respectively). We retained them in the group, however, in order to compare the same two groups as Yiamouyiannis and Burk had compared, 
Table 1 Observed to expected ratios and observed numbers of deaths in fluoridated (F) and non-fluoridated (NF) cities, using different US mortality rates to calculate expected numbers

OBSERVED TO EXPECTED RATIOS (observed numbers)

(a) Non-fluoridated cities (set 1)

\begin{tabular}{|c|c|c|c|c|c|}
\hline $\begin{array}{l}\text { Rates used in } \\
\text { calculation of } \\
\text { expected number }\end{array}$ & & 1950 & 1960 & 1970 & $\begin{array}{l}\text { Change } \\
1950-70 \\
\text { (per cent) }\end{array}$ \\
\hline 1950 rates & $\begin{array}{l}\mathbf{F} \\
\mathbf{N F}\end{array}$ & $\begin{array}{l}1.2302(21485) \\
1.1509(11 \quad 257)\end{array}$ & $\begin{array}{l}1.2420(23663) \\
1.1202(13094)\end{array}$ & $\begin{array}{l}1.2441(23405) \\
1.1725(14272)\end{array}$ & $\begin{array}{l}+1.13 \\
+1.88\end{array}$ \\
\hline 1960 rates & $\begin{array}{l}\text { F } \\
\text { NF }\end{array}$ & $\begin{array}{l}1.2212(21485) \\
1 \cdot 1465(11257)\end{array}$ & $\begin{array}{l}1.2289(23663) \\
1.1141(13094)\end{array}$ & $\begin{array}{l}1.2284(23405) \\
1 \cdot 1650(14272)\end{array}$ & $\begin{array}{l}+0.59 \\
+1.61\end{array}$ \\
\hline 1970 rates & $\begin{array}{l}\mathbf{F} \\
\text { NF }\end{array}$ & $\begin{array}{l}1 \cdot 1694(21485) \\
1 \cdot 1003(11257)\end{array}$ & $\begin{array}{l}1 \cdot 1743(23663) \\
1.0689(13094)\end{array}$ & $\begin{array}{l}1 \cdot 1754(23405) \\
1 \cdot 1210(14272)\end{array}$ & $\begin{array}{l}+0.51 \\
+1.88\end{array}$ \\
\hline
\end{tabular}

(b) Excluding Atlanta and Seattle from set 1 of non-fiuoridated cities

$\begin{array}{lll}\text { Same year } & \text { F } & 1 \cdot 2302(21485) \\ & \text { NF } & 1 \cdot 1457(9835) \\ 1950 \text { rates } & \text { F } & 1 \cdot 2302(21485) \\ & \text { NF } & 1 \cdot 1457(9835) \\ 1960 \text { rates } & \text { F } & 1 \cdot 2212(21485) \\ & \text { NF } & 1 \cdot 1420(9835) \\ 1970 \text { rates } & \text { F } & 1 \cdot 1694(21485) \\ & \text { NF } & 1.0962(9835)\end{array}$

$$
\begin{aligned}
& 1.2289(23663) \\
& 1.1204(11264)
\end{aligned}
$$

$1 \cdot 2289(23663)$

$1.0779(12737$

$1 \cdot 2420(23663)$

$1.0845(12737)$

$1.2289(23663)$

$1.0779(12737)$

$1 \cdot 1743(23663)$

$1.0352(12737)$
$1 \cdot 1754(23405)$
$1 \cdot 1239(12229)$
$1 \cdot 2441(23405)$
$1 \cdot 1750(12229)$
$1 \cdot 2284(23405)$
$1 \cdot 1679(12229)$
$1 \cdot 1754(23405)$
$1 \cdot 1239(12229)$

$-4 \cdot 45$

$-1.90$

$+1 \cdot 13$

$+2 \cdot 56$

$+0.59$

$+2 \cdot 27$

$+0.51$

$+2.53$

1970 rates

FF

NF
$1.2212(21$

$1 \cdot 1110(10456)$

$1 \cdot 1694(21485)$
$1.0674(10456)$

$1 \cdot 1784(23405)$
$1 \cdot 0904(15121)$
$1 \cdot 2441(23405)$
$1 \cdot 1416(15121)$
$1 \cdot 2284(23405)$
$1 \cdot 1332(15121)$
$1 \cdot 1754(23405)$
$1.0904(15121)$

$-4 \cdot 45$

$-2 \cdot 28$

$+1 \cdot 13$

$+2 \cdot 31$

$+0.59$

$+2 \cdot 00$

$+0.51$

$+2 \cdot 15$

This table incorporates corrections of errors in our 1977 paper to some of which we have already drawn attention.

and it did not seem reasonable to suspect that such a recent change could have influenced the mortality rates. As it happens, the exclusion of Atlanta and Seattle hardly affects the results at all; but in so far as it does, it serves only to emphasise the slightly greater deterioration of the non-fluoridated cities in comparison with the fluoridated ones over the period 1950 to 1970 (Table 1(b)).

THE SELECTION OF NON-FLUORIDATED CITIES The cities fluoridated before 1960 that were selected by Yiamouyiannis and Burk were the 10 largest fluoridated cities in the USA. The non-fluoridated cities (as of December 1969) that were selected for comparison were not, however, the largest, but the largest that also had crude cancer death rates in 1953 greater than 155 per 100000 persons per year. If the selection of the fluoridated group was made on the basis of size, it would have been more consistent if size had been the only criterion for choosing the non-fluoridated cities-even though some of them had lower crude cancer mortality rates in 1953 than the lowest rate observed in the fluoridated cities. Moreover, to select non-fluoridated cities on the basis of their having a high crude cancer death rate is to invite finding a smaller rise than average, because of the general tendency for extreme values to regress towards the mean. We have, therefore, repeated all the analyses using the 10 largest non-fluoridated cities in the USA at the time, as given by Yiamouyiannis and Burk ${ }^{5}$ irrespective of their cancer death rate in 1953, viz: Los Angeles, New Orleans, Boston, Columbus, Cincinnati, San Diego, San Antonio, Houston, Memphis, and Kansas City (that is, substituting San Diego, San Antonio, Houston, and Memphis for Atlanta, Newark, Portland, and Seattle).

Table 1(c) shows that the observed to expected ratio of deaths in this second set of non-fluoridated cities tended to rise slightly more over the period 1950 to 1970 than in the set used by Yiamouyiannis and Burk irrespective of whether the 1950,1960 , or 1970 national mortality rates were used to calculate the expected rates throughout. Alternatively, if the same year's mortality rates are used in the census years the fall in the rate is slightly less. In sum, the changes in these 10 non-fluoridated cities from 1950 to 1970 weigh very slightly more heavily against the claims of Yiamouyiannis and Burk ${ }^{25}$ than those in the 10 cities that they chose for comparison.

The populations by sex, age, and ethnic group of the different groups of cities are shown in Appendix 
Appendix Table A Populations of different groups of fluoridated and non-fluoridated US cities by age group, sex, and ethnic group

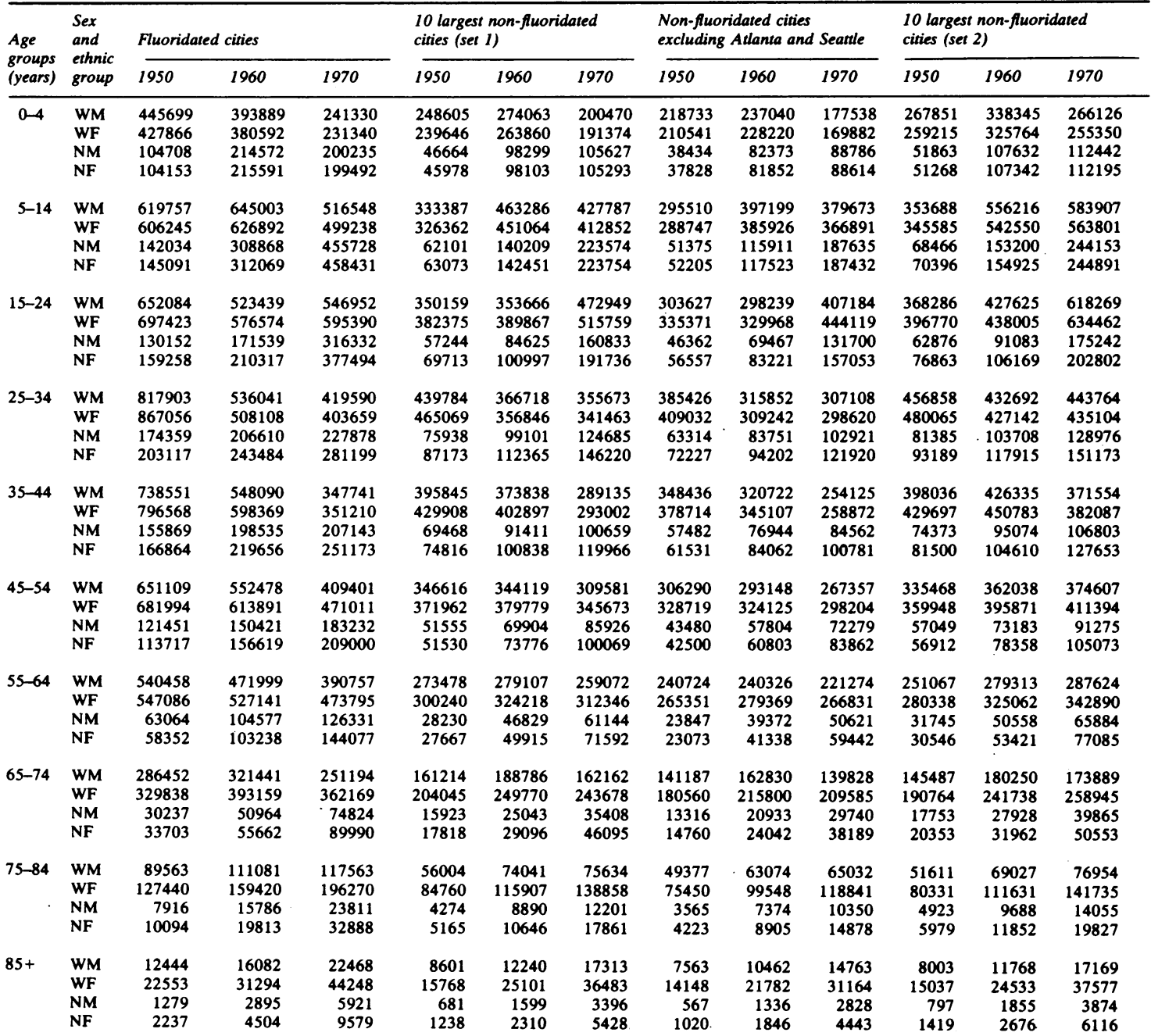

118857441150070310766632629007770755807342731549117260310386314927641376078498278757145

WM $=$ white males

WF $=$ white females

$\mathrm{NM}=$ non-white males

NF $=$ non-white females

Table A-the 10 fluoridated cities, the non-fluoridated cities (set 1) both including and excluding Atlanta and Seattle, and the 10 largest non-fluoridated cities (set 2). The US national cancer mortality rates for 1950,1960 , and 1970 are shown in Appendix Table B by sex, age, and ethnic group.

COMPARISON OF DIRECT AND INDIRECT METHODS OF STANDARDISING MORTALITY RATES

Yiamouyiannis and Burk have claimed that the indirect method of standardising cancer death rates in the two sets of cities in the USA was less appropriate than the direct method which they came to use, notwithstanding that, in their use, they classed both sexes and both ethnic groups together and used broad 20-year age groups. Reasons have been given repeatedly elsewhere for dismissing this claim. It is, however, now possible to compare the results of the direct and indirect methods using equally detailed data for both. Through the good offices of the US National Center for Health Statistics we have 
Appendix Table B Cancer mortality rates by age, sex, and ethnic group for the US in 1950, 1960, and 1970 and the rates in groups of fluoridated and non-fluoridated cities

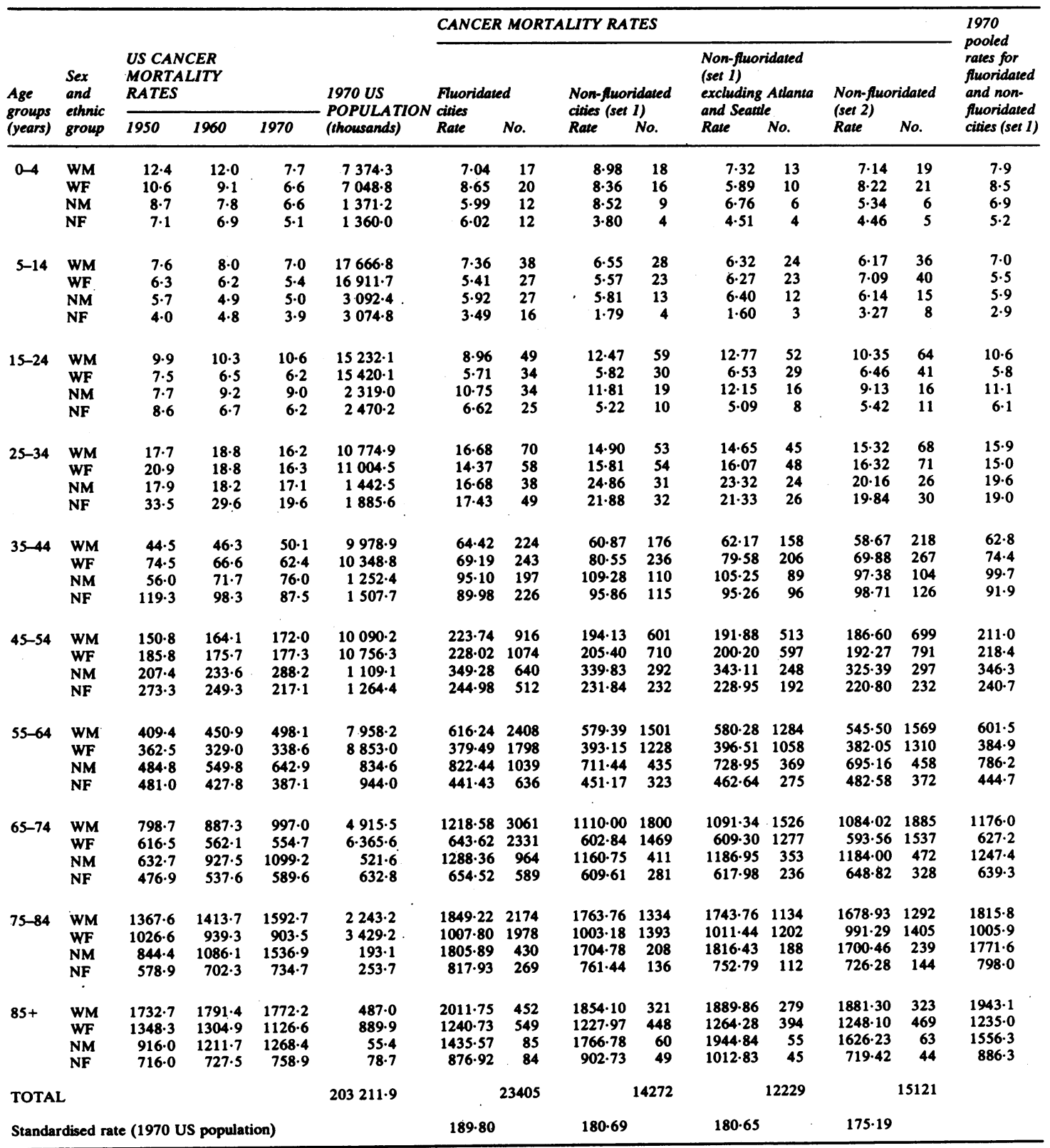

WM $=$ white males

WF $=$ white females

NM $=$ non-white males

NF $=$ non-white females

FLUORIDATED CITIES: San Francisco, Washington DC, Chicago, Baltimore, St. Louis, Buffalo, Cleveland, Philadelphia, Pittsburgh, Milwaukee. NON-FLUORIDATED CTIES (set 1): Wo Anges, Boston, Kansas City, Atlanta, Newark, Cincinatti, Portland, Seattle, New Orleans, Columbus. NON-FLUORIDATED CITIES (set 2): Los Angeles, New Orleans, Boston, Columbus, Cincinnati, San Diego, San Antonio, Houston, Memphis, Kansas (Missouri). 
Table 2 Comparison of mortality ratios (indirectly standardised) with directly standardised cancer mortality 'rates for both fluoridated and non-fluoridated cities in 1970

Indirect Direct

\begin{tabular}{|c|c|c|}
\hline Fluoridated & $1 \cdot 18$ & 189.80 \\
\hline$\overline{\text { Non-fluoridated (set 1) }}$ & $\overline{1 \cdot 12}=$ & $\overline{180.69}=1.05$ \\
\hline Fluoridated & $1 \cdot 18$ & 189.80 \\
\hline $\begin{array}{l}\text { Non-fluoridated (set 1) } \\
\text { excluding Atlanta and Seattle }\end{array}$ & $\overline{1.12}$ & $\overline{180.65}$ \\
\hline Fluoridated & $1 \cdot 18$ & $189 \cdot 80$ \\
\hline Non-fluoridated (set 2) & 1.09 & $175 \cdot 19$ \\
\hline
\end{tabular}

obtained the numbers of deaths from cancer in all of the cities concerned by sex, ethnic group, and 10-year age group in 1970 (Appendix Table B) and so we have been able to use the direct method of standardisation in an adequate way. No anomalies were evident in an examination of the age, sex, and ethnic group specific mortality rates recorded for each group of cities. These rates have been used to calculate the numbers of deaths that would have occurred in the entire United States of America if the population had experienced the same rates. By using the rates shown in Appendix Table $B$ and the corresponding populations for 1970 in Appendix Table A, we have obtained directly standardised rates for comparison with those obtained by the indirect method. The results, which are shown in Table 2, are identical. It was not possible to obtain corresponding data for the other two census years, 1950 and 1960 , because the National Center for Health Statistics no longer held the basic data.
CALCULATION OF SMRS USING POOLED DATA FOR 20 CITIES

It is also now possible to use the pooled experience of the two sets of cities to constitute the standard population for the calculation of standardised mortality ratios by the indirect method. In this way we can examine the effect of our earlier use of national data as standards for comparing the mortality in sets of cities that were not typical of the country as a whole. The pooled mortality rates are shown in Appendix Table B and the results obtained by using them are shown in Table 3 . The results show clearly and incontrovertibly that the mortality rates are almost identical in the two sets of cities when sex, age, and ethnic group are taken into account, and that the very slight excess in the fluoridated cities is proportionately less in 1970 than in 1950 . Our conclusion is unaltered. The ideal comparison would require the use of pooled mortality rates in 1950 to calculate the expected numbers of deaths in 1950 and the pooled rate in 1960 to calculate the expected numbers in 1960, but unfortunately these are now irretrievable.

\section{Conclusion}

The mortality from cancer in the 10 largest cities in the USA that have had fluoridated water supplies since before 1957 was somewhat higher in 1970 than in the large non-fluoridated cities that we have examined. The relative excess has not increased since 1950 , if allowance is made for changes in the sex, age, and ethnic group constitution of the population by any of the standard methods. On the contrary, it has

Table 3 Expected numbers and observed to expected ratios using pooled cancer mortality rates in 1970 for the original 20 cities




decreased slightly no matter which of the appropriate methods of comparison is chosen.

We thank Angela Hewitt for help with the analyses and the National Center for Health Statistics, Maryland, for making available mortality data relating to the cities covered by this study.

Reprints from Dr. L. J. Kinlen, University of Oxford, Radcliffe Infirmary, Oxford OX2 6HE.

\section{References}

${ }^{1}$ Burk D, Yiamouyiannis J. Letter (21 July). Congressional Record 1975; 191: H 7172-6 Washington DC: US Government Printing Office.
2Yiamouyiannis J, Burk D. Letter (16 December). Congressional Record 1975; 191: H 12731-4. Washington DC: US Government Printing Office.

${ }^{3}$ Kinlen L, Doll R. Fluoridation of water and cancer mortality in the USA. Lancet 1977; i: 1300-2.

4 Kinlen L, Doll R. Cancer and fluoride. Lancet 1977; ii: 1039.

${ }^{5}$ Yiamouyiannis J, Burk D. Fluoridation and cancer: age dependence of cancer mortality related to artificial fluoridation. Fluoride 1977; 10: 102-23.

${ }^{6}$ Oldham PD, Newell DJ. Fluoridation of water supplies and cancer-a possible association. Appl Stat 1977; 26: 125-35.

${ }^{7}$ Doll R. Fluoridation and cancer. Lancet 1977; ii: 296.

${ }^{8}$ Smith AH. An examination of the relationship between fluoridation of water and cancer mortality in 20 large US cities. New Zealand Med J 1980; 91: 413-6. 